\title{
Equipoise and the ethics of the Canadian Lung Volume Reduction Surgery Trial study: Should there be a randomized, controlled trial to evaluate lung volume reduction surgery?
}

\author{
John D Miller MD FRCSC ${ }^{1}$, Michael D Coughlin $\mathrm{PhD}^{2}$, Lori Edey MDiv ${ }^{3}$, \\ Patricia Miller MHSc ${ }^{4}$, Yasmin Sivji MBBS MPH ${ }^{5}$ \\ ${ }^{1}$ Division of Thoracic Surgery, St Joseph's Hospital, McMaster University; ${ }^{2}$ Hospital Ethics \\ Service, St Joseph's Hospital; ${ }^{3}$ Pastoral Education, McMaster University; \\ ${ }^{4}$ Physiotherapy, McMaster University; ${ }^{5}$ Canadian Lung Volume Reduction Surgery \\ National Trial Coordinator, McMaster University, Hamilton, Ontario
}

JD Miller, MD Coughlin, L Edey, P Miller, Y Sivji. Equipoise and the ethics of the Canadian Lung Volume Reduction Surgery Trial study: Should there be a randomized, controlled trial to evaluate lung volume reduction surgery? Can Respir J 2000;7(4):329-332.

The physical improvement is so great following lung volume reduction surgery that there is growing opinion that a randomized, controlled trial is unnecessary. A randomized, controlled trial, it is argued, would deprive those patients randomly assigned to the nonsurgical treatment arm the 'benefit' of lung volume reduction surgery. Entering a trial in which one arm leads to a surgical intervention and the other to best medical management also poses a variety of ethical difficulties. If one is to be offered surgery, there must be perceived benefit because the physician has an obligation to offer the best possible treatment for his or her patient. If a patient agrees to have surgery, the expectation is that surgery would help. Thus, a patient randomly assigned to the medical arm of a trial may easily believe that he or she is being deprived of surgery that may help them. This paper illustrates this dilemma using the Canadian Lung Volume Reduction Surgery Trial. The authors discuss the concept of 'equipoise' in three dimensions, adding community equipoise to theoretical equipoise and clinical equipoise earlier described by Freedman. The paper concludes that the Canadian Lung Volume Reduction Surgery Trial needs to continue because of the clinical equipoise that drives it.

Key Words: Clinical equispoise; Community equipoise; Equipoise; Lung volume reduction surgery; Theoretical equipoise 


\section{Équilibre et dilemme moral : est-il justifié de mener un essai sur échantillon aléatoire et con- trôlé pour évaluer la réduction chirurgicale du volume pulmonaire? Tel est le cas du Canadian Lung Volume Reduction Surgery Trial}

L'amélioration physique à la suite d'une réduction chirurgicale du volume pulmonaire est telle que de plus en plus de voix clament qu'il n'est pas nécessaire de mener un essai sur échantillon aléatoire et contrôlé. Elles font valoir que ce genre d'essai prive les patients dirigés au hasard vers le groupe de traitement non chirurgical des « bienfaits » de la réduction chirurgicale du volume pulmonaire. Le fait d'être admis dans un essai comportant deux groupes de traite- ment, l'un chirurgical, l'autre médical (le meilleur qui soit) pose également d'autres problèmes d'ordre moral. Si un patient se voit offrir le traitement chirurgical, il faut en déduire que l'opération procure des bienfaits, parce que le médecin a l'obligation d'offrir le meilleur traitement possible. Si le patient accepte d'être opéré, c'est que l'intervention est salutaire. Aussi un patient dirigé au hasard vers le groupe de traitement médical peut-il facilement se croire privé des bienfaits potentiels de l'intervention. Le présent article fait état du dilemme auquel fait face l'essai Canadian Lung Volume Reduction Trial. Les auteurs discutent du concept de l'équilibre tridimensionnel, ajoutant l'axe communautaire aux axes théoriques et cliniques déjà décrits par Freedman. Ils en arrivent à la conclusion que l'essai doit se poursuivre en raison de l'axe clinique qui le sous-tend.
$\mathrm{L}$ ung volume reduction (LVR) is a surgical procedure that appears to offer unmatched improvement in pulmonary function for a select group of patients with emphysema. The physical improvement is so great that there is growing opinion that a randomized, controlled trial (RCT) to evaluate the merit of LVR is unnecessary. An RCT, it is argued, would deprive patients randomly assigned to the nonsurgical treatment arm the 'benefit' of LVR. To justify ethically a clinical trial in which some patients do not receive the potentially beneficial treatment, equipoise must exist; that is, there must exist a state of genuine uncertainty regarding the comparative therapeutic merits of each arm of the trial.

Equipoise, as defined in Webster's Ninth New Collegiate Dictionary (1), is a "state of equilibrium", a "counter balance". Each side of a balance has equal weight. In clinical practice, it is rare for any individual physician to give exactly equal weight to different treatment options for a condition (Figure 1). There is usually a preference. Given this, and the obligation that physicians have to propose treatment that they consider best for their patients, there is some question as to how a physician could ethically enter a patient into a randomized, controlled trial. When examining this dilemma, Freedman (2) introduced a distinction between theoretical equipoise and clinical equipoise.

Theoretical equipoise exists in a situation in which there is absolutely no preference for one treatment or another, with the evidence on behalf of two alternative treatment regimes being exactly balanced. This evidence may be derived from a variety of sources, including data from the literature, considerations of basic science and fundamental physiological processes, uncontrolled experience and perhaps even 'gut' feeling or instinct (3). Theoretical equipoise applied to a clinical trial is overwhelmingly fragile and easily disturbed by any slight accretion of evidence favouring one arm of the trial.

Clinical equipoise exists when there is a current or imminent conflict in the clinical community over a treatment preference for patients in a defined population. In this situation, there exists an honest, professional disagreement among experts about the preferred treatment. The clinical trial is the way to resolve this dispute. Clinical equipoise can exist even when individual physicians have a preference because it looks to the state of uncertainty in the community of physicians, not in the individual physician (2).

Both concepts of equipoise focus on treatment decisions from the perspective of the clinicians offering the treatment. It is now recognized that decisions regarding treatment options about innovative therapies must also involve those receiving or seeking the therapies. This involvement must consist of more than simply consent to enter a trial proposed by a physician. It involves the patient's independent judgement of the uncertainty regarding the different treatment options. We might call this community equipoise.

Community equipoise includes patients and their values. While clinical equipoise is required to justify the trial from the perspective of those offering the treatment - physicians or investigators - community equipoise is important to justify the trial from the perspective of those seeking the therapy (the patient and the patient's family).

The community of those who may be entered into a trial needs to acknowledge the uncertainty about the merits of different treatment options within the trial. This requires information about treatment options and integrated reflection in light of individual, family and cultural values. Until recently, information has often been limited because few people had access to independent knowledge that would affect their preference for entry into a particular arm in a trial. However, the general increase in medical knowledge and the increasingly sophisticated access to specialized, often opinionated, information is creating a community that is much more actively involved in treatment evaluation and decisionmaking. This has been especially prevalent in the treatment of human immunodeficiency virus/AIDS (4).

Clearly, the state of uncertainty within community equipoise is very fragile. Information within the community at large (the patient, the patient's family and the general population) is variable in quality and can very easily instill a bias regarding treatment options. The lay press, radio and television media, the Internet and word of mouth often report with a limited perspective, instilling bias. 
Biases and a loss of equipoise can also arise when the only aspect of a treatment considered is efficacy (5). Treatments can be evaluated and compared not only on the basis of efficacy but on toxicity or morbidity, on ease of administration, compliance or perceived quality of life, and a number of other factors. Thus, if the only information being provided or considered is on efficacy, community equipoise may be disturbed, while clinical equipoise might be unaffected because it includes consideration of the other aspects of a treatment.

\section{EQUIPOISE AND LVR SURGERY}

LVR surgery is logical and physiologically sound. Numerous case series of LVR surgery have benefitted a carefully selected group of patients with emphysema (efficacy). The improvement in pulmonary function is unmatched by other medical or surgical treatments for this patient population. However, evaluation of a treatment includes more than efficacy. Although LVR offers substantial, potential benefits, these benefits are associated with considerable risk and come with a high price. Most case series report mortality rates in the range of $5 \%$ to $10 \%$, and a morbidity of up to $20 \%$, because of factors such as a prolonged intensive care stay on life support (6).

At the time of the reintroduction of LVR in 1995, there was little information about its efficacy and risk. In the intervening five years, a great deal has been written about LVR including two important physiological papers $(7,8)$, a number of case series $(6,7,9,11,12)$ with one using case controls for comparison (13), and numerous editorials and review papers. There have been no RCTs comparing LVR with best available medical management. There remains uncertainty about the clinical usefulness of LVR and about the treatment to which it should be compared. Although a great deal has been learned about improved medical management, our understanding about the survival of patients with severe emphysema is based on older, outdated information from the decades before the introduction of immunization, steroids, oxygen and rehabilitation as standard care. The impact of current best medical practice on outcomes, such as recurrent hospitalizations and longevity, has not been well quantified. Thus, uncertainty remains about the long term efficacy of LVR compared with the efficacy of pulmonary rehabilitation and best medical management. The risk and/or benefit in both LVR and best medical practice (with cardiorespiratory rehabilitation) have not yet been compared in an RCT.

The Canadian Lung Volume Reduction (CLVR) study (14) compares best medical care with pulmonary rehabilitation with and without the addition of LVR in a multicentred study. The primary outcome is a Health Utility Index that follows the patient population over two years and allows an assessment of quality of life that includes death of an individual in the patient population score for each treatment arm. The Health Utility Index over time yields a value known as quality-adjusted-life-years. The broad-based, multicentred nature of the trial will not only answer the question about efficacy, but should provide an important statement about effectiveness. The trial will not only answer the question "can

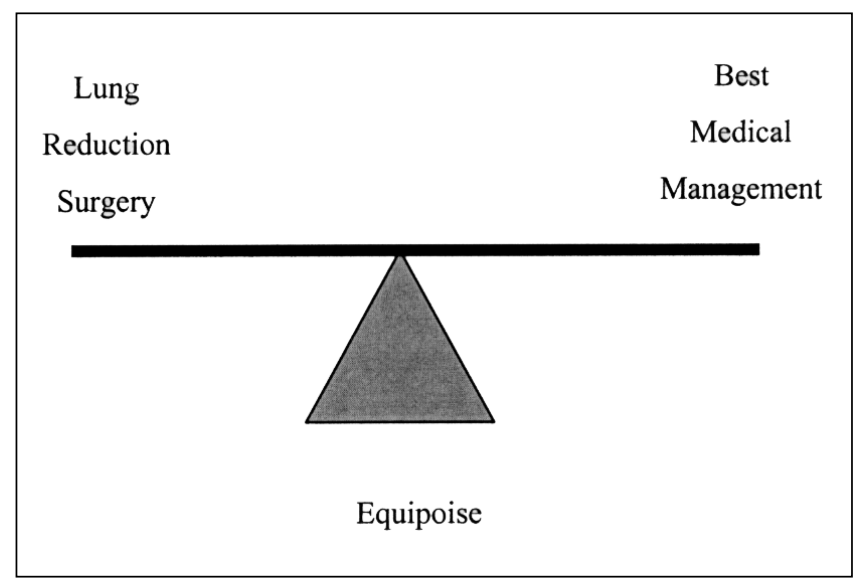

Figure 1) As schematically depicted by this stylized scale, equipoise exists when there is equal weight (value) to both lung reduction surgery and best medical management within the scientific community (clinical equipoise) and the patient community (community equipoise)

LVR surgery work? (efficacy)', but will help address the question 'does lung volume reduction surgery work when offered to patients across Canada? (effectiveness)'.

For some physicians and surgeons, theoretical equipoise in this trial is disturbed and their professional bias strongly favours one arm of an LVR trial over the other. In the United States, a collection of signatures on a document (15) outlining the belief that lung reduction surgery "provides clear benefit to a known segment of late stage emphysema patients" has been signed by 75 university surgeons and respirologists. This document has been presented to the United States Congress requesting that LVR be made available through Medicare. This is evidence that theoretical equipoise is disrupted for these surgeons and respirologists. However, does it truly represent a consensus? In Canada, it appears that theoretical equipoise is also disturbed but favours medical management. Patient referrals for LVR are low for many reasons. One reason appears to be that the general health expectations for patients with emphysema are not as high in Canada as they are in the United States. For example, it is a common preoperative criterion in the United States to expect patients to be able to exercise for 30 consecutive minutes on a stationary cycle. In Canada, most physicians do not refer patients for LVR (or a trial) if they can achieve 30 min on a cycle because the patient is not felt to be sick enough. Even if one ignores the fact that this criterion is unreliable, theoretical equipoise seems to be personal and idiosyncratic. Both in Canada and the United States, a bias is developing that is sufficient to disrupt theoretical equipoise but not clinical equipoise. The level of clinical evidence has not yet reached a high enough standard to affect clinical equipoise.

History is replete with surgical treatment options for dyspnea that were strongly favoured for a period, but fell from favour later as public opinion, interest or evidence failed to support them. These include procedures such as pleurectomy to improve vascularity to the lungs (16), lung denervation to reduce airway narrowing (17), external strutting of the major airways to reduce dynamic collapse (18), tracheoplasty to 
reduce the size of the hemithorax (19) and glomectomy to reduce dyspnea (20). Thus, it is important to persevere with the clinical appraisal of these two different approaches.

The results of the LVR reported in the CLVR trial (6) and other case series in the literature $(10-12,16)$ may be purely an artifact of the research methods used. Also, the current level of evidence is not strong enough to be convincing. We know that we can effect significant changes in pulmonary function testing and exercise capacity. However, what about the effect of lung reduction surgery on survival and quality of life? How long will the pulmonary function improvement last? How long will patients live after LVR? What are the costs associated with LVR? Finally, how does it compare with other treatment options? The CLVR trial will evaluate and compare the risks and benefits of both LVR and best medical management with pulmonary rehabilitation.

Community equipoise: The reports of success and the personal testimonials of patients undergoing LVR have captured the attention of many patients and families who suffer from end-stage emphysema. It is the responsibility of the medical community and of media to provide balanced and accurate reporting so that patients and families are not misled by the promise of future new treatment options. Patients with information about only the potential benefit may try to obtain the operation rather than enter a trial in which they may not be in the treatment (LVR) group. Clearly, for those patients who are seeking a 'miracle cure', there is no equipoise.

However, it is the responsibility of the investigator to inform the patient of the current state of knowledge, to review the risks and benefits, and then discuss the trial. Patients need to be encouraged to reflect upon their own individual, familial and cultural values in light of this information about treatment options. Balance within the treatment team supports the patients' abilities to achieve community equipoise. Patients should not be conscripted to serve as subjects in clinical trials. Rather, the information provided to patients must be sufficiently balanced to allow them to evaluate the options, and, if appropriate, appreciate the extent of the existing uncertainty and its implications for them. Patients must have their own sense of equipoise (community equipoise) before enrolling in a trial.

\section{CONCLUSIONS}

LVR surgery has become accepted by many surgeons and specialists within the medical community. Patients and their families desperately seek a 'miracle cure' for patients with end-stage emphysema. Nevertheless, because published data concerning the safety and efficacy of this procedure are currently lacking, a more prudent course is required. More information must be developed before recommending this treatment to symptomatic patients with emphysema. We will need to define those patients who are most likely to benefit from the procedure with low risks of morbidity and mortal- ity. We also need to address the issues of cost and long term survival.

The CLVR Surgery Trial continues with enthusiasm. The study will yield important information for clinicians, health care decision makers, patients and families. This methodologically rigorous RCT is essential to assess adequately the value of LVR surgery to patients with emphysema. Both theoretical and community equipoise are fragile and can easily be disturbed. Clinical equipoise, however, continues to drive the need for an RCT. We feel that the clinical community requires a higher level of evidence than is currently available to determine the efficacy and effectiveness of LVR surgery.

\section{REFERENCES}

1. Webster's Ninth New Collegiate Dictionary. Frederick C Mish, ed. Markham: Thomas Allen and Son Ltd, 1991.

2. Freedman B. Equipoise and the ethics of clinical research. N Engl J Med 1987;317:141-5.

3. Shafer A. The ethics of the randomized clinical trial. N Engl J Med 1982;307:719-24.

4. Freedman B. Nonvalidated therapies and HIV disease. Hastings Centre Rep 1989;19:14-20.

5. Freedman B. A response to a purported ethical difficulty with randomized clinical trials involving cancer patients. J Clinical Ethics 1992:3:231-4.

6. Miller JD, Malthaner R, Goldsmith $\mathrm{CH}$, et al. Lung volume reduction surgery for emphysema and the Canadian Lung Volume Reduction Surgery (CLVR) Project. Can Respir J 1999;6:26-32.

7. Ingenito EP, Evans RB, Loring SH, et al. Relationship between preoperative inspiratory lung resistance and the outcome of lung volume reduction surgery for emphysema. N Engl J Med 1998;338:1181-5.

8. Sciurba FC, Rogers RM, Keenan RJ, et al. Improvement in pulmonary function and elastic recoil after lung reduction surgery for diffuse emphysema. N Engl J Med 1996;334:1095-9.

9. Delarue NC, Woolf CR, Sander DE, et al. Surgical treatment of pulmonary emphysema. Can J Surg 1977;20:222-31.

10. Cooper JD, Trulock EP, Triantafillou AN, et al. Bilateral pueumectomy (volume reduction) for chronic obstructive pulmonary disease. J Thorac Cardiovasc Surg 1995;109:106-9.

11. Mckenna RJ Jr, Brenner M, Fischer RJ, Gelb AF. Should lung volume reduction surgery be unilateral or bilateral? J Thorac Cardiovasc Surg 1996;112:1331-9.

12. Snell GI, Solin P, Chin W, et al. Lung volume reduction surgery for emphysema. Med J Aust 1997;167:529-32.

13. Myers BF, Yusenn RD, Lefrak SS, et al. Outcome of Medicare patients with emphysema selected for, but denied, a lung volume reduction operation. Ann Thorac Surg 1998;66:331-6.

14. (CLVR) Surgery Trial. http://www.CLVR.org. (December 1999).

15. Lung Reduction Surgery Advisory Group. December 1998 Consensus Statement on Lung Volume Reduction Surgery. Presented before US Congress, December 1998.

16. Eschapasse H, Berthoumieu F. La chirurgie de l'emphyseme pulmonaire. Bronchpneumologie 1980;30:173-81.

17. Abbott OA, Hopkins WA, Van Fleit WE, Robinson JS. A new approach to pulmonary emphysea. Thorax 1953;8:116-3.

18. Surgical therapy for expiratory collapse of the trachea and large bronchi. In: Grillo H, Eschapasse H, eds. International Trends in General Thoracic Surgery. Philadelphia: WB Saunders, 1987:74-90.

19. Allison PR. Giant bullous cysts of the lung. Thorax 1947;2:169.

20. Nakayama K. Surgical removal of the carotid body for bronchial asthma. Diseases of the Chest 1961;40:595-604. 


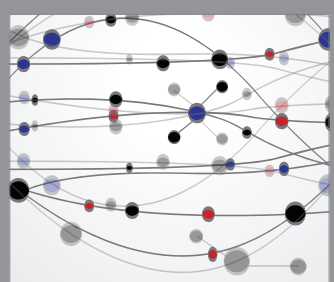

The Scientific World Journal
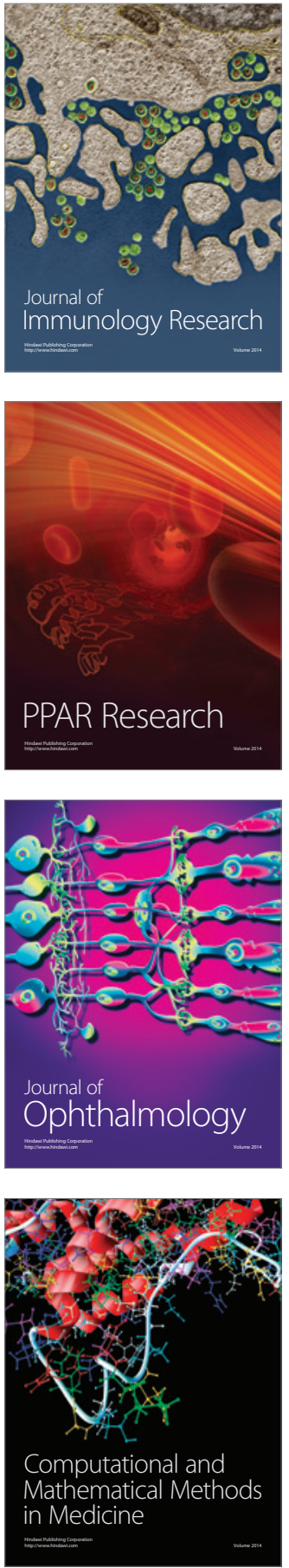

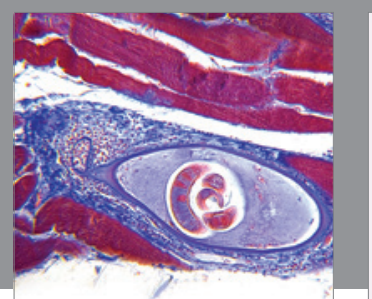

Gastroenterology Research and Practice

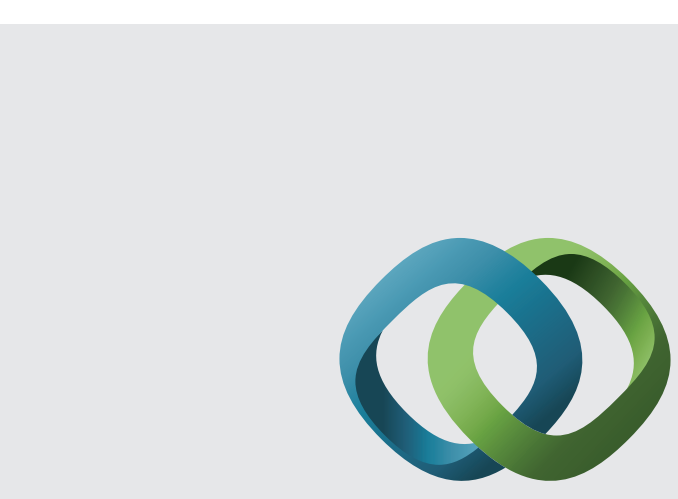

\section{Hindawi}

Submit your manuscripts at

http://www.hindawi.com
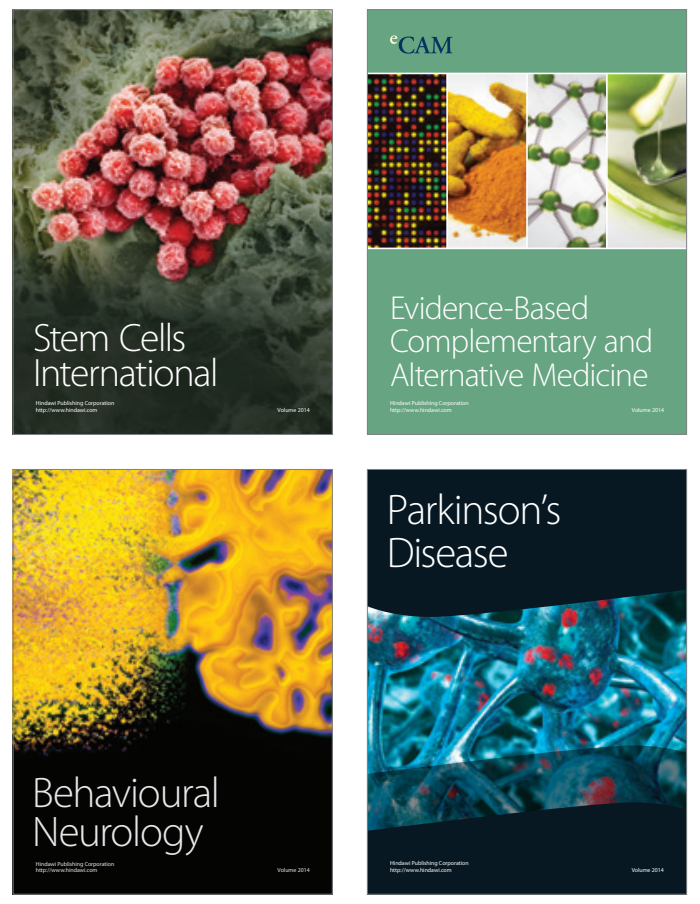
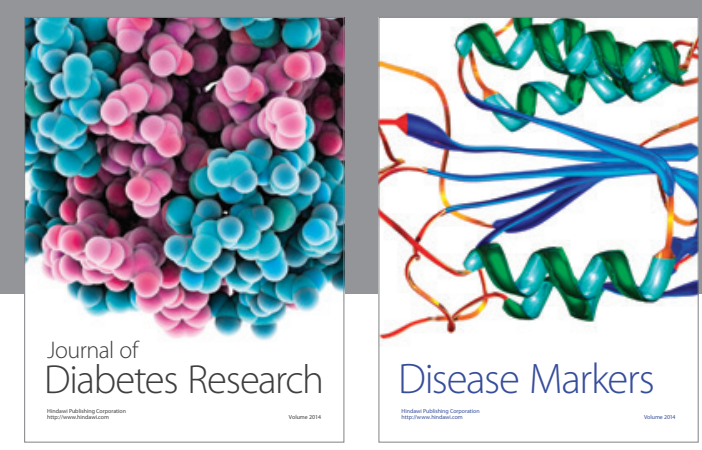

Disease Markers
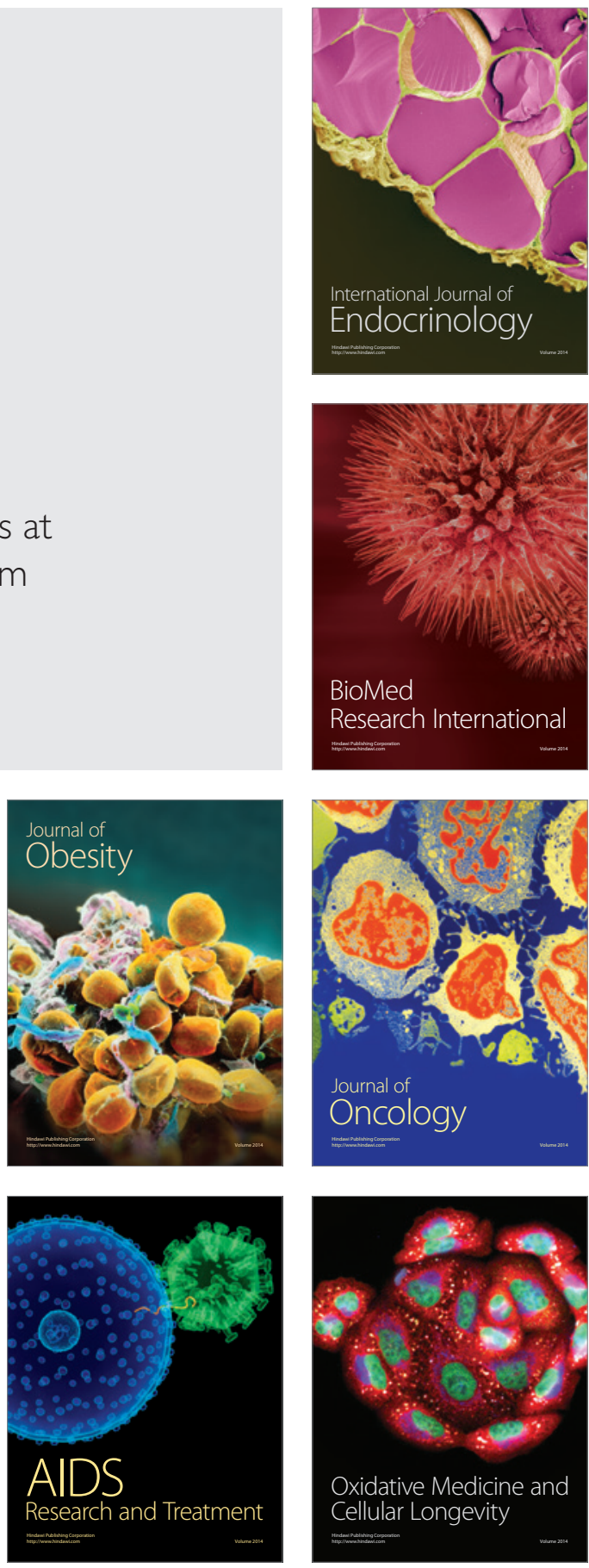